\title{
Asthma and the Coronavirus Disease 2019 Pandemic: A Literature Review
}

\author{
Mário Morais-Almeida ${ }^{\mathrm{a}, \mathrm{b}}$ Helena Pité ${ }^{\mathrm{a}-\mathrm{c}}$ Rita Aguiar ${ }^{\mathrm{a}}$ Ignacio Ansotegui $^{\mathrm{d}}$ \\ Jean Bousquet ${ }^{\mathrm{e}-\mathrm{g}}$ \\ ${ }^{a}$ Allergy Center, CUF Descobertas and CUF Infante Santo Hospitals, Lisbon, Portugal; ${ }^{b}$ Portuguese Association of \\ Asthmatics (APA), Porto, Portugal; ' CEDOC, Chronic Diseases Research Center, NOVA Medical School, Universidade \\ NOVA de Lisboa, Lisbon, Portugal; d Allergy Department, Hospital Quironsalud Bizkaia, Bizkaia, Spain; ${ }^{\text {eHospital }}$ \\ Charité, Universitätsmedizin Berlin, Humboldt-Universität zu Berlin, Berlin, Germany; ${ }^{\mathrm{f}}$ Department of Dermatology \\ and Allergy, Comprehensive Allergy Center, Berlin Institute of Health, Berlin, Germany; ${ }^{9}$ MACVIA-France, \\ Montpellier, France
}

\section{Keywords}

Asthma · Coronavirus disease 2019 • COVID-19 · Allergy ·

Risk factors - T2 inflammation

\begin{abstract}
Even though respiratory viruses are one of the most common triggers for asthma exacerbations, not all of these viruses affect patients equally. There is no strong evidence supporting that patients with asthma have a higher risk of becoming seriously ill from coronavirus disease 2019 (COVID-19), although recent reports from the USA and the UK suggest that asthma is much more common in children and adults with mild to severe COVID-19 than has previously been reported in Asia and in Europe. As in previous severe acute respiratory syndrome (SARS) outbreaks, patients with asthma, especially children, appear to be less susceptible to the coronavirus with a low rate of asthma exacerbations. A different expression of viral receptors and T2 inflammation can be responsible for different outcomes. Future studies focused on asthma and on other allergic disorders are needed to provide a greater understanding of the impact of underlying asthma and allergic inflammation on COVID-19 susceptibility and disease severity. However, for the moment, it is
\end{abstract}

karger@karger.com www.karger.com/iaa

Karger"

$$
\text { 兴 }
$$

crucial that asthmatic patients maintain their controller medication, from inhaled corticosteroids to biologics, without making any dose adjustments on their own or stopping the medication. New data are emerging daily, rapidly updating our understanding of this novel coronavirus.

(c) 2020 S. Karger AG, Basel

\section{Introduction}

A new coronavirus (severe acute respiratory syndrome coronavirus 2; SARS-CoV-2) infection began to spread in Wuhan, China, in early December 2019 and has rapidly spread around the globe. The disease condition associated with this novel coronavirus is referred to as coronavirus disease 2019 (COVID-19), and this outbreak was declared a pandemic on March 11, 2020, by the World Health Organization (WHO) [1]. As of May 15, 2020, the outbreak had reached globally 4,580,498 confirmed cases and 305,618 deaths, and only 1,735,657 patients had recovered [2]. These numbers are much greater than those

Edited by: H.-U. Simon, Bern. (c) 2020 S. Karger AG, Base
Rita Aguiar

Allergy Center, CUF Descobertas Hospital

Rua Mário Botas

PT-1998-018 Lisbon (Portugal)

aguiar2016@gmail.com 
Table 1. Asthma prevalence in COVID-19 studies

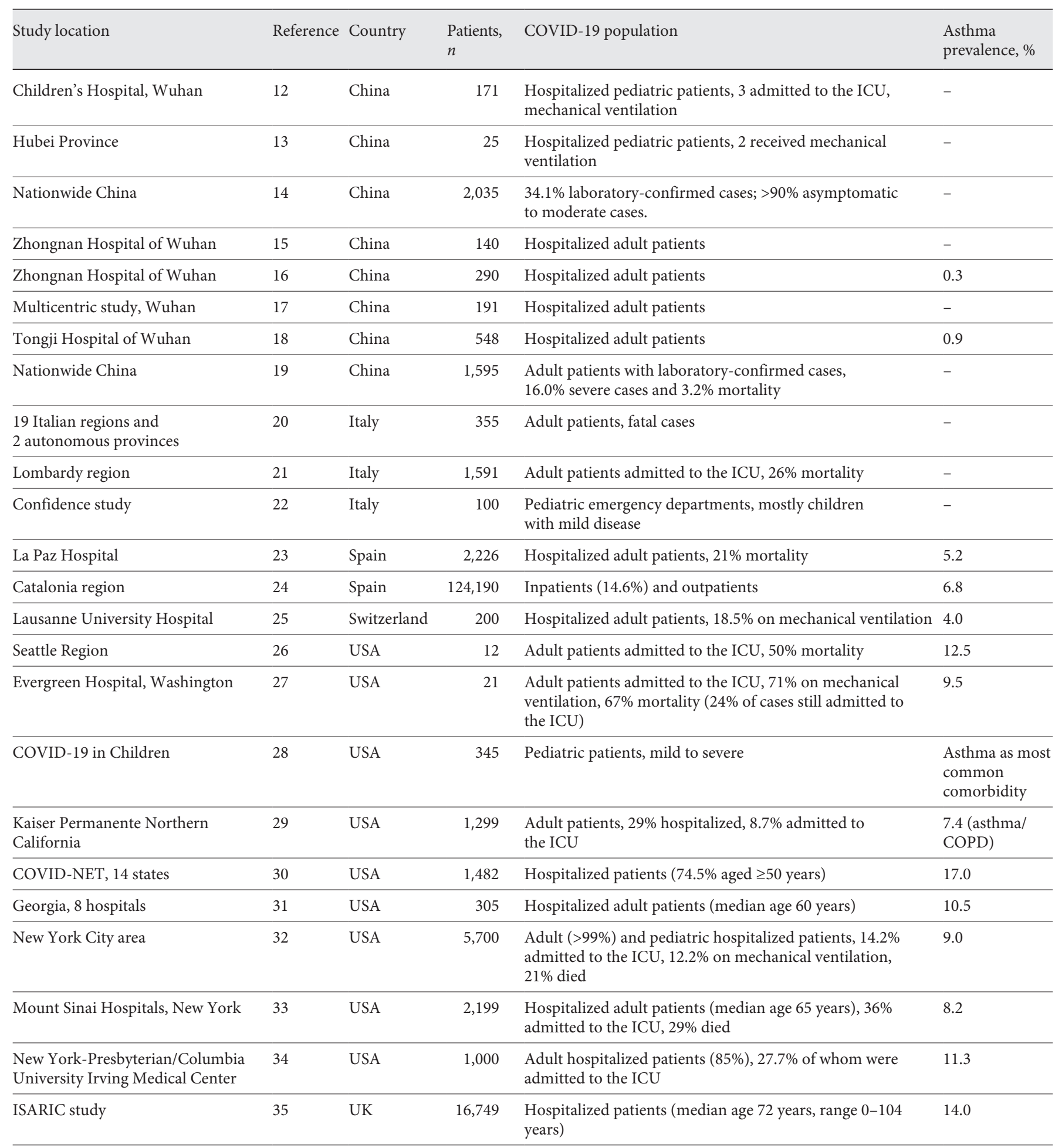


Table 1 (continued)

\begin{tabular}{|c|c|c|c|c|c|}
\hline Study location & Reference & Country & $\begin{array}{l}\text { Patients, } \\
n\end{array}$ & COVID-19 population & $\begin{array}{l}\text { Asthma } \\
\text { prevalence, } \%\end{array}$ \\
\hline $\begin{array}{l}\text { OpenSAFELY case control } \\
\text { populational study }\end{array}$ & 36 & UK & 5,683 & Fatal cases & $\begin{array}{l}\text { Asthma with a } \\
\text { higher risk of } \\
\text { COVID-19 } \\
\text { death; HR = } \\
1.1-1.25 \text { (no or } \\
\text { recent use of } \\
\text { OCS) }\end{array}$ \\
\hline UK BioBank & 37 & UK & 605 & Hospitalized adult patients (median age 57.4 years) & 17.9 \\
\hline Middle East region & 39 & Saudi Arabia & 150 & $\begin{array}{l}\text { Hospitalized patients (median age } 46 \text { years), } 10.7 \% \\
\text { admitted to the ICU }\end{array}$ & 2.7 \\
\hline $\begin{array}{l}\text { Epidemiological Surveillance System } \\
\text { for Viral Respiratory Diseases of the } \\
\text { Mexican Ministry of Health }\end{array}$ & 40 & Mexico & 10,554 & $\begin{array}{l}\text { Patients with laboratory confirmed SARS-CoV-2, 39.4\% } \\
\text { were hospitalized and } 9.2 \% \text { were fatal cases }\end{array}$ & 3.6 \\
\hline
\end{tabular}

Mexican Ministry of Health

registered during the SARS and Middle East respiratory syndrome (MERS) pandemics, which occurred in 2003 and 2013, respectively [3], despite the fact that the COVID-19 mortality rate, to date, is lower $[2,3]$.

SARS-CoV-2 binds mainly to angiotensin converting enzyme 2 (ACE2) receptors in host cells which are abundant in the lungs, heart, blood vessels, and intestine and, after more than a decade of research, there are still no specific treatments or effective vaccines for coronavirus [3-6].

COVID-19 presents with respiratory symptoms, from mild to severe, and a significant percentage of patients develop acute respiratory disease syndrome (ARDS); these severe symptoms are associated with a true cytokine storm, in particular IL-6, and death can be one of the outcomes [7].

Old age and underlying morbidities, such as cardiovascular diseases, in particular hypertension and metabolic disorders (obesity and diabetes), have been identified as significant risk factors for COVID-19 morbidity and mortality [7-9]. However, asthma and COPD may not be common comorbidities [10]. Moreover, the real impact of SARS-CoV-2 in asthma control is unclear.

\section{Methods}

A systematic search was carried out in the following 4 electronic databases: EMBASE, MEDLINE, MedRxiv, and Scopus to assess the relationship between asthma and COVID-10 using studies in the English language up to May 14, 2020. The search terms included were: "COVID-19" OR "SARS-CoV-2" OR "Coronavirus" AND "Asthma" OR "Allergy" OR "Case series" OR "Comorbidi- ties" OR "Epidemiology" OR "Hospitalization" OR "Risk factors." Additionally, the references of the initial included studies were hand searched to identify other possibly eligible studies.

\section{Literature Review}

Results from the first epidemiologic studies of the COVID-19 pandemic in China apparently did not identify asthma as a risk factor of severe COVID-19 [10, 11]. Of 171 children treated at Wuhan Children's Hospital (Wuhan, China), 3 (1.8\%) required intensive care and mechanical ventilation; all of them had underlying diseases but there was no asthma reference [12]. The same data was found in a cross-sectional multicenter study carried out in 10 hospitals across Hubei province (China), including hospitalized children with COVID-19 [13] (Table 1).

Dong et al. [14] (China), in a nationwide case series of 2,135 pediatric patients (mean age 7 years) with COVID-19, observed cases at the Chinese Center for Disease Control and Prevention from January 16, 2020, to February 8, 2020 (Hubei Province) and did not report any asthma case.

In a survey of 140 adult patients admitted with COVID-19 (China), the clinical characteristics and allergy status of the patients was investigated. All of the patients were community-acquired cases. Hypertension (30.0\%) and diabetes mellitus (12.1\%) were the most common comorbidities. Drug hypersensitivity (11.4\%) and urticaria (1.4\%) were self-reported by several patients. Asthma or other allergic diseases were not reported by any of the patients and the authors concluded that allergic diseases and asthma were not risk factors for SARS-CoV-2 infection. An older age and a high number of comorbidities, i.e., cardiovascular and metabolic diseases, were associated with COVID-19 severity [15]. The same authors studied a larger sample of 290 confirmed COVID-19 adult patients who were hospitalized, and they found only 1 patient with asthma $(0.3 \%)$; once again, hypertension and diabetes mellitus were the most frequently found comorbidities [16].

In another retrospective, multicenter cohort study that included 191 adult inpatients with confirmed COVID-19 (Wuhan, China), $48 \%$ had at least 1 comorbid disease, with hypertension being the most common, followed by diabetes and coronary heart dis- 
ease, with no asthma reference [17]. In a survey of 70 adult patients admitted with COVID-19 in Tongji Hospital (Wuhan, China), an asthma prevalence rate of $0.9 \%$ was found; this is markedly lower than that in the adult population in this region (6.4\%) [18]. In this study, asthma was not identified as a risk factor for disease severity, in contrast with hypertension [18].

A nationwide analysis from China [19], including 1,590 COVID-19 cases from 575 hospitals in 31 provincial administrative regions, reported an overall rate of severe cases and mortality of 16.0 and $3.2 \%$, respectively. The most prevalent comorbidity was hypertension (16.9\%), followed by diabetes (8.2\%). One hundred thirty $(8.2 \%)$ patients reported having 2 or more comorbidities. None of the cases had physician-diagnosed asthma. After adjusting for age and smoking status, COPD ( $\mathrm{HR}=2.681$; 95\% CI $1.424-$ $5.048)$, diabetes $(\mathrm{HR}=1.59 ; 95 \%$ CI 1.03-2.45), hypertension $(\mathrm{HR}=1.58 ; 95 \% \mathrm{CI} 1.07-2.32)$, and malignancy $(\mathrm{HR}=3.50 ; 95 \%$ CI 1.60-7.64) were identified as significant severity risk factors, including for intensive care unit (ICU) admission, mechanical ventilation, and death [19].

In Europe, in a sample of 355 patients with COVID-19 who died in Italy (with a mean age of 79.5 years) it was reported that comorbidities were associated with an increased mortality risk. Thirty percent of patients had ischemic heart disease, $35.5 \%$ had diabetes, $20.3 \%$ had active cancer, $24.5 \%$ had atrial fibrillation, $6.8 \%$ had dementia, and $9.6 \%$ had a history of stroke. Once again, no reference to chronic respiratory diseases was made, i.e., asthma or chronic obstructive pulmonary disease (COPD) [20].

Also in a retrospective case series of 1,591 consecutive patients with laboratory-confirmed COVID-19 admitted to ICU in 72 hospitals of the Lombardy Region in Italy between February 20 and March 18, 2020, 68\% of the patients had at least 1 comorbidity. Hypertension was the most common comorbidity, affecting $49 \%$ of the 1,043 patients with available data. The second most common comorbidities were cardiovascular disease (21\%) and hypercholesterolemia (18\%). Only $4 \%$ had a history of COPD, with no reference to patients with asthma [21].

In the CONFIDENCE study [22] that included 100 pediatric COVID-19 cases also from Italy (median age 3.3 years; $58 \%$ with mild disease and only $1 \%$ with severe disease), there was no reference to chronic respiratory diseases as was found in previous pediatric Chinese surveys by Lu et al. [12] and Dong et al. [14].

Borobia et al. [23] from La Paz University Hospital, Madrid, Spain, in a sample of 2,226 adult patients (median age 61 years) admitted to hospital who either died $(20.7 \%)$ or were discharged (79.3\%), identified that the most common comorbidity was hypertension (41.3\%), followed by other chronic cardiovascular diseases $(19.3 \%)$ and diabetes (17.1\%); asthma was identified in $5.2 \%$ of COVID-19 patients, with a lower prevalence rate of $3.7 \%$ in the fatal cases. COPD affected $6.9 \%$ of the population, with a prevalence of $14.1 \%$ in the fatal cases. Also from Spain, in Catalonia, Prieto-Alhambra et al. [24] analyzed a primary care database covering $>6$ million people, including 121,263 COVID-19 patients (both hospitalized and outpatients). Most common comorbidities were hypertension (24.3\%) and obesity (19.9\%). Asthma was present in $6.8 \%$ of the patients and COPD was found in $3.2 \% ; 10.7 \%$ of all patients were treated with inhalers.

In 200 COVID-19 patients hospitalized in the Lausanne University Hospital, Switzerland, [25] an asthma prevalence rate of $4.0 \%$ was found; the asthma prevalence rate was $2.7 \%$ in those patients who required mechanical ventilation.
In the USA, Bhatraju et al. [26] (Seattle, WA, USA) reported 24 patients with COVID-19 admitted to the ICU with a mortality rate of $50 \%$. As coexisting disorders, $58 \%$ had diabetes, $22 \%$ were current or former tobacco smokers, $21 \%$ had chronic kidney disease, and $14 \%$ had asthma, corresponding to 3 cases with mild asthma who had been treated with systemic corticosteroids in the week before ICU admission, as outpatients, for a presumed asthma exacerbation. These patients were subsequently admitted to the ICU with severe respiratory failure requiring invasive mechanical ventilation [26].

Arentz et al. [27] (WAUSA) described, in a case series, the characteristics and outcomes of 21 patients with COVID-19 admitted to the ICU at Evergreen Hospital, with a mean age of 70 years (range 43-92 years); the more common comorbidities identified were: chronic kidney disease (47.6\%), congestive heart failure (42.9), diabetes (33.3\%), and COPD (33.3\%). Two patients had asthma (9.5\%).

Data from the USA regarding 345 cases in children ( $<18$ years) showed that $23 \%$ had at least 1 comorbidity [28]. Chronic respiratory diseases, i.e., asthma, were the most common associated diseases, although the authors did not quantify the prevalence. Comorbidities were more frequently present in pediatric patients who required hospitalization compared to those who were not admitted to hospital (77 vs. 12\%), but there was no reference to asthma as a significant risk factor [28].

In a sample of 377 adult COVID-19 patients admitted to California (USA) hospitals, $7.4 \%$ had nondiscriminated asthma or COPD [29]. A data analysis of patients hospitalized in 14 states of the USA with COVID-19 during March 2020 ( $n=1,482)$ [30] confirmed that hospitalization was much more frequent in adults (74.5\% aged $\geq 50$ years). Among patients with information on underlying conditions $(n=120), 89 \%$ had 1 or more comorbidities. The most common were hypertension and other cardiovascular diseases (77.5\%), followed by obesity (48.3\%) and diabetes mellitus (28.3\%). Seventeen percent of the COVID-19-positive patients had asthma and $10.7 \%$ had COPD. According the Centers for Disease Control and Prevention (CDC) report, in admitted patients aged 18-49 years, obesity was the most prevalent underlying condition (59.0\%), followed by asthma (27.3\%) [30].

A report from 8 hospitals (Georgia, USA), also summarized medical data for 305 adult patients with confirmed COVID-19 who were admitted during March 2020. Overall, 225 (73.8\%) patients had underlying conditions. Hypertension (67.5\%), diabetes (39.7\%), other cardiovascular diseases $(25.6 \%)$ were found, as was severe obesity $(B M I \geq 40)$, which was present in $12.7 \%$ of patients. Asthma was identified in $10.5 \%$ of all of the patients $(13.5 \%$ in patients aged $18-49$ years, $13.1 \%$ in those aged $50-64$ years, and $6.0 \%$ in those aged $\geq 65$ years, with no statistically significant differences) and COPD in 5.2\% [31].

In the large sample of hospitalized COVID patients ( $>99 \%$ adults), that included 5,700 patients hospitalized with COVID-19 in the New York City area (NY, USA), $14.2 \%$ were treated in the ICU, $12.2 \%$ received invasive mechanical ventilation, and $21 \%$ died [32]. An asthma prevalence was found in $9.0 \%$ (with no reference to asthma severity/control) and COPD was found in $5.4 \%$; the most common comorbidities were hypertension (56.6\%), obesity (41.7\%), and diabetes (33.8\%) [32].

In the NY Mount Sinai Hospitals, an $8.2 \%$ prevalence of asthma was found in 2,199 of hospitalized patients; it was not significantly different in those who died (7.4\%) [33]. Also in NY (USA), in the first 1,000 consecutive adult patients with a positive SARS-CoV-2 PCR test who presented to the emergency department or were hos- 
pitalized at New York-Presbyterian/Columbia University Irving Medical Center between March 1 and April 5, 2020, an asthma prevalence of $11.3 \%$ was found; it was also not significantly different in those that were admitted to the ICU (12.3\%) [34].

In the ISARIC Prospective Observational Cohort Study [35] with near real-time analysis, with the participation of 166 UK hospitals, 16,749 COVID-19 hospitalized patients were included between February 6 and April 18, 2020 (mostly adults). The commonest comorbidities were chronic cardiac disease (29\%), uncomplicated diabetes (19\%), non-asthmatic chronic pulmonary disease (19\%), and asthma (14\%); 47\% had no documented reported comorbidity. Increased age and comorbidities including obesity were associated with a higher probability of mortality [35].

Very recent data from the OpenSAFELY Collaborative Study [36] identified asthma as a significant risk factor of death from COVID-19 in England (UK). The authors conducted a cohort study that included $17,425,445$ adults using national primary care electronic health record data linked to in-hospital COVID-19 death data (from February 1, 2020, to April 25, 2020). An older age age was strongly associated with risk, with the age group $\geq 80$ years having a more than 12-fold increased risk compared to those aged 50 59 years; most comorbidities were associated with a higher risk of COVID-19 hospital death, including asthma (fully adjusted HR = $1.11 ; 95 \% 1.02-1.20)$, with a greater HR for those with recent use of an oral corticosteroid (OCS) (HR = 1.25; 95\% CI 1.08-1.44) [36].

Data from the UK Biobank [37], in a prospective case-control study, showed an asthma prevalence of $17.9 \%$ in 605 COVID-19 hospitalized patients, most of them adults (the asthma prevalence was of $13.5 \%$ in the control population) but the disease was not identified as an independent risk factor for COVID-19 hospitalization/severity, in contrast with hypertension and COPD. In the oldest population (age $\geq 65$ years) included in the UK Biobank [38], the same tendency of asthma prevalence was found between hospitalized COVID-19 patients versus controls (18.2 vs. $13.0 \%$ ), but again asthma was not identified as an independent risk factor for severity.

In a report from the Middle East (Saudi Arabia) [39] that included 150 hospitalized adult patients (mean age 46.1 years), it was found that 28.8 and $26.0 \%$ of the COVID-19 population had hypertension and diabetes, respectively. The asthma prevalence was $2.7 \%$, and 1 patient with asthma was admitted to the ICU.

In a study aiming to estimate the risk factors for hospitalization and death in a Mexican population [40] infected with SARS-CoV-2 ( $n=10,554$, mean age 46.5 years; $39.4 \%$ hospitalized and $9.2 \%$ fatal cases), hypertension was the most prevalent comorbidity found $(21.7 \%)$, followed by obesity $(20.15 \%)$ and diabetes $(17.7 \%)$. The asthma prevalence was $3.6 \%$ of this population $(3.1 \%$ in the hospitalized patients and in $3.2 \%$ in the fatal cases). Patients with hypertension, obesity, and diabetes were more likely to be hospitalized and die than people without these comorbidities. Once again, asthma was not identified as an independent risk factor for hospitalization and/or mortality [40].

\section{Discussion}

Based on the available literature, there was no clear evidence that patients with asthma were at a higher risk of being infected or becoming severely ill with SARS-
CoV-2, although recent reports from the USA and the UK suggest that asthma is much more common in children and adults with COVID-19 than was previously reported in Asia and in the first surveys in continental Europe.

Nevertheless, the prevalence of several underlying conditions identified in US hospitalized patients with COVID-19 was similar to those for hospitalized influenza patients during influenza seasons 2014-15 through 201819 , i.e., regarding chronic respiratory diseases (29-31\%) [41].

Of particular note in the UK is the association of asthma with a higher risk of COVID-19 hospital death, with the HR increasing further for those who received OCS, probably indicating a greater severity of disease. This contrasts with previous findings, in several countries, where asthma and other chronic respiratory diseases have been underrepresented in hospitalized patients [36]. Also in the UK asthma was reported in 14.0 and $17.9 \%$ of hospitalized patients but with no increased risk of death [35, 37].

Among school age children, viral infection reportedly accounts for up to $85 \%$ of asthma exacerbations, and viruses are more frequently isolated from symptomatic patients than from asymptomatic patients [42, 43]. Even though respiratory viruses are one of the most common triggers for asthma exacerbations in all age groups, not all of these viruses affect patients equally. In particular, the human rhinovirus was identified as the main individual contributor for asthma exacerbations, with coronavirus being one of the less identified triggers of asthma exacerbations in children as well as in adults [44]. A recent literature review concerning virus detection during asthma exacerbations confirmed that exacerbations were mainly associated with rhinovirus infection in all continents [45].

In previous SARS outbreaks, patients with asthma, in particular children, appeared to be less susceptible to the coronavirus, with a reported low rate of asthma exacerbations and a good prognosis on follow-up [10,46]. In contrast, during influenza epidemics, asthma was associated with more severe disease, including the need for mechanical ventilation, not only in adults but also in children [47]. The exact reasons for this remain unknown, but it was confirmed during the current coronavirus pandemic [48].

From the recent COVID-19 literature, no definite conclusions can be drawn regarding asthma control or severity. Similarly, no information can be extrapolated about asthma phenotypes, i.e., regarding whether asthma is allergic or not. 
COVID-19 outcomes vary from asymptomatic infection to death and it is possible that this clinical range reflects different airway levels of the SARS-CoV-2 receptor, ACE2, and the spike protein activator transmembrane protease serine 2 (TMPRSS2), considering that the virus cell entry also depends on S-protein priming by host cell proteases.

Blood eosinophil levels are a well-known predictor of airway T2 inflammation [49], and the measurement of blood eosinophil levels can be used as an accessible (not strong), proxy for investigation of the association between airway T2 inflammation and COVID-19 outcomes.

In early reports from China, a detailed clinical investigation of hospitalized COVID-19 cases suggested severe eosinopenia together with lymphopenia as a potential indicator of the diagnosis and to a worse prognosis, including death [15]. It was believed that low eosinophil counts in peripheral blood would be related to the SARS-CoV-2 infection itself. However, more recent studies from China and from Italy have not reported eosinopenia in patients with severe COVID-19 [26, 31, 50].

Although the relationship between eosinophil counts and COVID-19 is uncertain, attention is warranted to monitor eosinophil counts among patients with asthma who are using biological therapies that lead to decreased eosinophil counts and the clinical course of COVID-19 in cases infected with the SARS-CoV-2 [51].

Sajuthi et al. [52] studied in children the role of both T2 inflammation and viral infection in regulating the gene expression of ACE2 and TMPRSS2 and they found a strong influence of T2 cytokine-driven inflammation on both ACE2 (downregulation) and TMPRSS2 (upregulation) expression levels, which can have clinical implications for COVID-19 outcomes. In contrast, the authors found an equally strong positive influence of respiratory virus infections on ACE2 expression [52]. So, at least theoretically, in patients with asthma and high T2 inflammation, the consequence of an interferon-dependent inflammation requires close monitoring given the enhanced risk of complications due to SARS-CoV-2 infection.

A recent study that included asthma patients from 3 different cohorts of children and adults found that ACE2 receptor expression was lower in those patients with high allergic sensitization, but nonatopic asthma was not associated with this reduced expression [53]. These data suggest that this reduced ACE2 expression may be a potential contributor, among several other factors, of reduced COVID-19 severity in patients with respiratory allergies, i.e., allergic asthma [53].

Asthma and the COVID-19 Pandemic
Additionally, there is some early evidence coming from the Severe Asthma Research Program-3 (SARP), that inhaled corticosteroid therapy is also associated with reduction on ACE2 and TMPRSS2 gene expression from sputum [54]. These data stress the importance of maintain asthma controlled using the treatment according to the best practices, including with inhaled steroids.

There is also evidence to support that taking ICS may be beneficial in dealing coronavirus infections. In vitro studies have shown inhibitory actions of budesonide on coronavirus $\mathrm{HCoV}-229 \mathrm{E}$ replication and cytokine production [55], and preliminary not yet peer-reviewed data suggest that ciclesonide blocks SARS-CoV-2 ribonucleic acid replication [56] and inhibits its cytopathic activity [57], which may have clinical implications.

Although gene expression for ACE2 and TMPRSS2 did not differ in healthy and asthmatic patients, it was also found that males, African Americans, and patients with diabetes have increased expression of ACE2 and TMPRSS2 in their sputum cells, which may be associated with the poor prognosis of these patients when infected with the SARS-CoV-2 [54].

Dong et al. [58] very elegantly described selected cases of patients with COVID-19 (children and adults), demonstrating the profile complexity and different clinical presentations from mild to severe cases. Patients with common allergic diseases, such as rhinitis or atopic dermatitis, did not develop distinct symptoms or had severe courses, which may suggest a positive balance of type 2 immune regulation in COVID-19 pathogenesis.

New data are emerging daily, rapidly updating our understanding of this novel coronavirus, but it is crucial that patients with asthma and other allergic diseases such as allergic rhinitis maintain their controller medication, from inhaled corticosteroids to biologics $[51,59,60]$, including allergen immunotherapy [61], without making any dose adjustments on their own or stopping medication, which may lead to a higher risk of asthma exacerbations, increased OCS use, and a higher probability of the need for emergency room access and hospitalization (risk factors for coronavirus exposure and spread). Likewise, it is important to maintain well-controlled rhinitis and rhinosinusitis, together with other known risk factors for asthma exacerbations [62].

The available data about OCS use in asthma exacerbations, though limited to 3 reported cases in mild asthmatics [26], are in accordance with data from previous coronavirus outbreaks, showing that systemic corticosteroids can be associated with a higher viral load $[63,64]$. The UK data suggesting an increased death risk in patients

Int Arch Allergy Immunol 2020;181:680-688 685 
with asthma, especially in those who recently received systemic steroids [36], stress that clinicians must be cautious and recognize the differences between hypoxic respiratory failure and bronchospasm to carefully balance the need for OCS prescription [51], and bronchodilators must be delivered by metered dose inhalers with spacers in order to prevent the viral spread related with nebulizer use [65].

As was shown by Kaye et al. [66], there is evidence of increased adherence to asthma (and COPD) pharmacologic treatment during the first months of COVID-19, which is encouraging and hopefully will have a positive effect on improvement of the control of asthma and minimize the need for acute care for this inflammatory chronic respiratory disease.

In conclusion, it is unclear whether patients with asthma are at a higher risk of developing COVID-19 and/or becoming severely ill. Future studies in all age groups are needed to provide a greater understanding of the impact of underlying asthma, other allergic diseases, and T2 inflammation on COVID-19 susceptibility and disease out- comes. The better we understand these interactions, the better we will be able protect the most vulnerable people, including those in high-risk groups.

\section{Conflict of Interest Statement}

The authors have no conflict of interests to declare related to this work.

\section{Funding Sources}

No funding was received for the publication of this paper.

\section{Author Contributions}

The named authors meet the International Committee of Medical Journal Editors (ICMJE) criteria for authorship of this paper. M.M.-A. performed data extraction from the literature and drafted this paper. J.B. significantly contributed to the conception of and critically reviewed this paper. All of the authors reviewed and approved the final draft for publication.

\section{References}

1 World Health Organization. WHO DirectorGeneral's opening remarks at the media briefing on COVID-19: 11 March 2020. 2020 [cited 2020 Mar 27]. Available from: https:// www.who.int/dg/speeches/detail/who-director-general-s-opening-remarks-at-the-media-briefing-on-covid-19--11-march-2020.

2 Worldometer. COVID-19 coronavirus pandemic. 2020 [cited 2020 May 15]. Available from: https://www.worldometers.info/coronavirus/.

3 Wang Y, Wang Y, Chen Y, Qin Q. Unique epidemiological and clinical features of the emerging 2019 novel coronavirus pneumonia (COVID-19) implicate special control measures. J Med Virol. 2020 Mar;92(6):568-76.

$4 \mathrm{Wu} \mathrm{F}$, Zhao S, Yu B, Chen YM, Wang W, Song ZG, et al. A new coronavirus associated with human respiratory disease in China. $\mathrm{Na}$ ture. 2020 Mar;579(7798):265-9.

5 Abassi ZA, Skorecki K, Heyman SN, Kinaneh S, Armaly Z. Covid-19 infection and mortality: a physiologist's perspective enlightening clinical features and plausible interventional strategies. Am J Physiol Lung Cell Mol Physiol. 2020 May;318(5):L1020-2.

6 Sanders JM, Monogue ML, Jodlowski TZ, Cutrell JB. Pharmacologic treatments for coronavirus disease 2019 (COVID-19): a review. JAMA. 2020;323(18):1824-36.

7 Lupia T, Scabini S, Mornese Pinna S, Di Perri G, De Rosa FG, Corcione S. 2019 novel coronavirus (2019-nCoV) outbreak: a new challenge. J Glob Antimicrob Resist. 2020 Mar;21: 22-7.
8 Yang J, Zheng Y, Gou X, et al. Prevalence of comorbidities and its effects in coronavirus disease 2019 patients: a systematic review and meta-analysis. Int J Infect Dis. 2020;94:91-5.

9 Fang L, Karakiulakis G, Roth M. Are patients with hypertension and diabetes mellitus at increased risk for COVID-19 infection? Lancet Respir Med. 2020 Apr;8(4):e21.

10 Halpin DM, Faner R, Sibila O, Badia JR, Agusti A. Do chronic respiratory diseases or their treatment affect the risk of SARS-CoV-2 infection? Lancet Respir Med. 2020 May;8(5): 436-8.

$11 \mathrm{Wu} Z$, McGoogan JM. Characteristics of and important lessons from the Coronavirus Disease 2019 (COVID-19) outbreak in China: summary of a report of 72,314 cases from the Chinese Center for Disease Control and Prevention. JAMA. 2020 Feb;323(13):1239-42.

$12 \mathrm{Lu} \mathrm{X}$, Zhang L, Du H, Zhang J, Li YY, Qu J, et al.; Chinese Pediatric Novel Coronavirus Study Team. SARS-CoV-2 infection in children. N Engl J Med. 2020 Apr;382(17):16635 .

13 Zheng F, Liao C, Fan QH, Chen HB, Zhao XG, Xie ZG, et al. Clinical characteristics of children with Coronavirus Disease 2019 in $\mathrm{Hu}$ bei, China. Curr Med Sci. 2020 Apr;40(2): 275-80.

14 Dong Y, Mo X, Hu Y, Qi X, Jiang F, Jiang Z, et al. Epidemiology of COVID-19 among children in China. Pediatrics. 2020 Jun; 145(6):e20200702.

15 Zhang JJ, Dong X, Cao YY, Yuan YD, Yang $Y B$, Yan YQ, et al. Clinical characteristics of
140 patients infected with SARS-CoV-2 in Wuhan, China. Allergy. 2020, doi: 10.1111/ all.14238.

16 Zhang JJ, Cao YY, Dong X, Wang BC, Liao MY, Lin J, et al. Distinct characteristics of COVID-19 patients with initial rRT-PCRpositive and rRT-PCR-negative results for SARS-CoV-2. Allergy. 2020. doi: 10.1111/ all.14316.

17 Zhou F, Yu T, Du R, et al. Clinical course and risk factors for mortality of adult inpatients with COVID-19 in Wuhan, China: a retrospective cohort study. Lancet. 2020 Mar 28; 395(10229):1054-62.

18 Li X, Xu S, Yu M, et al. Risk factors for severity and mortality in adult COVID-19 inpatients in Wuhan. J Allergy Clin Immunol. 2020. doi: 10.1016/j.jaci.2020.04.006.

19 Guan WJ, Liang WH, Zhao Y, Liang HR Chen ZS, Li YM, et al.; China Medical Treatment Expert Group for COVID-19. Comorbidity and its impact on 1590 patients with COVID-19 in China: a nationwide analysis. Eur Respir J. 2020 May;55(5):2000547.

20 Onder G, Rezza G, Brusaferro S. Case-fatality rate and characteristics of patients dying in relation to COVID-19 in Italy. JAMA. 2020; 323(18):1775-6.

21 Grasselli G, Zangrillo A, Zanella A, Antonelli M, Cabrini L, Castelli A, et al.; COVID-19 Lombardy ICU Network. Baseline characteristics and outcomes of 1591 patients infected with SARS-CoV-2 admitted to ICUs of the Lombardy Region, Italy. JAMA. 2020 Apr; 323(16):1574. 
22 Parri N, Lenge M, Buonsenso D; Coronavirus Infection in Pediatric Emergency Departments (CONFIDENCE) Research Group. Children with Covid-19 in pediatric emergency departments in Italy. N Engl J Med. 2020. doi: 10.1056/NEJMc2007617.

23 Borobia AM, Carcas AJ, Arnalich F, et al; for the COVID@HULP Working Group. A cohort of patients with COVID-19 in a major teaching hospital in Europe. medRxiv. 2000. Available from: https://doi.org/10.1101/2020. 04.29.20080853.

24 Prieto-Alhambra D, Balló E, Coma E, et al. Hospitalization and 30-day fatality in 121,263 COVID-19 outpatient cases. medRxiv, 2020. Available from: https://doi.org/10.1101/2020. 05.04.20090050.

25 Regina J, Papadimitriou-Olivgeris M, Burger R, Filippidis P, Tschopp J, Desgranges F. Epidemiology, risk factors and clinical course of SARS-CoV-2 infected patients in a Swiss university hospital: an observational retrospective study. medRxiv. 2020 Available from: https://doi.org/10.1101/2020.05.11.20097741.

26 Bhatraju PK, Ghassemieh BJ, Nichols M, Kim $\mathrm{R}$, Jerome KR, Nalla AK, et al. Covid-19 in critically ill patients in the Seattle region: case series. N Engl J Med. 2020 May;382(21): 2012-22.

27 Arentz M, Yim E, Klaff L, Lokhandwala S, Riedo FX, Chong M, et al. Characteristics and outcomes of 21 critically ill patients with COVID-19 in Washington State. JAMA. 2020 Mar;323(16):1612. Epub ahead of print.

28 Bialek S, Gierke R, Hughes M, McNamara LA, Pilishvili T, Skoff T; CDC COVID-19 Response Team. Coronavirus disease 2019 in children: United States, February 12-April 2, 2020. MMWR Morb Mortal Wkly Rep. 2020 Apr;69(14):422-6.

29 Myers LC, Parodi SM, Escobar GJ, Liu VX. Characteristics of hospitalized adults with COVID-19 in an integrated health care system in California. JAMA. 2020 Apr;323(21):2195.

30 Garg S, Kim L, Whitaker M, O'Halloran A, Cummings C, Holstein R, et al. Hospitalization rates and characteristics of patients hospitalized with laboratory-confirmed Coronavirus Disease 2019: COVID-NET, 14 states, March 1-30, 2020. MMWR Morb Mortal Wkly Rep. 2020 Apr;69(15):458-64.

31 Gold JA, Wong KK, Szablewski CM, Patel PR, Rossow J, da Silva J, et al. Characteristics and clinical outcomes of adult patients hospitalized with COVID-19: Georgia, March 2020. MMWR Morb Mortal Wkly Rep. 2020 May; 69(18):545-50.

32 Richardson S, Hirsch JS, Narasimhan M, Crawford JM, McGinn T, Davidson KW, et al.; Northwell COVID-19 Research Consortium. Presenting characteristics, comorbidities, and outcomes among 5700 patients hospitalized with COVID-19 in the New York City area. JAMA. 2020 Apr;323(20):2052.

33 Paranjpe I, Russak AJ, De Freitas JK, Lala A, Miotto R, Vaid A. Clinical characteristics of hospitalized Covid-19 patients in New York
City. medRxiv. 2020. Available from: https:// doi.org/10.1101/2020.04.19.20062117.

34 Argenziano MG, Bruce SL, Slater CL, Tiao JR, Baldwin MR, Hamilton GR, et al. Characterization and clinical course of 1000 patients with COVID-19 in New York: retrospective case series. medRxiv. 2020. Available from: https://doi.org/10.1101/2020.04.20.20072116.

35 Docherty AB, Harrison EM, Green CA, et al. Features of 16,749 hospitalised UK patients with COVID-19 using the ISARIC WHO clinical characterisation protocol. medRxiv. 2020. Available from: https://doi.org/10.1101 /2020.04.23.20076042.

36 Williamson E, Walker AJ, Bhaskaran K, Bacon S, Bates C, Morton CE; The OpenSAFELY Collaborative. OpenSAFELY: factors associated with COVID-19-related hospital death in the linked electronic health records of 17 million adult NHS patients. medRxiv. 2020. Available from: https://doi.org/10.1101 /2020.05.06.20092999.

37 Khawaja AP, Warwick AN, Hysi PG, et al. Associations with covid-19 hospitalisation amongst 406,793 adults: the UK Biobank prospective cohort study. medRxiv. 2020. Available from: https://doi.org/10.1101/2020.05.06 .20092957.

38 Atkins JL, Masoli JÁ, Delgado J, et al. Preexisting comorbidities predicting severe COVID-19 in older adults in the UK Biobank community cohort. medRxiv. 2020. Available from: https://doi.org/10.1101/2020.05.06.200 92700.

39 Shabrawishi M, Al-Gethamy MM, Naser AY, et al. Clinical, radiological and therapeutic characteristics of patients with COVID-19 in Saudi Arabia. medRxiv. 2020. Available from: https:// doi.org/10.1101/2020.05.07.20094169.

40 Carrillo-Veja MF, Salinas-Escudero G, García-Peña C, Gutiérrez-Robledo LM, ParraRodríguez L. Early estimation of the risk factors for hospitalisation and mortality by COVID-19 in México. medRxiv. 2020. Available from: https://doi.org/10.1101/2020.05.11.200 98145.

41 Centers for Disease Control and Prevention. FluView interactive: laboratory-confirmed influenza hospitalizations. 2020 [cited 2020 Apr 24]. Available from: https://www.cdc. gov/flu/weekly/fluviewinteractive.htm.

42 Johnston SL, Pattemore PK, Sanderson G, Smith S, Lampe F, Josephs L, et al. Community study of role of viral infections in exacerbations of asthma in 9-11 year old children. BMJ. 1995 May;310(6989):1225-9.

43 Papadopoulos NG, Christodoulou I, Rohde G, Agache I, Almqvist C, Bruno A, et al. Viruses and bacteria in acute asthma exacerbations-a GA ${ }^{2}$ LEN-DARE systematic review. Allergy. 2011 Apr;66(4):458-68.

44 Satia I, Cusack R, Greene JM, O’Byrne PM, Killian KJ, Johnston N. Prevalence and contribution of respiratory viruses in the community to rates of emergency department visits and hospitalizations with respiratory tract infections, chronic obstructive pulmonary disease and asthma. PLoS One. 2020 Feb; 15(2):e0228544.

45 Zheng XY, Xu YJ, Guan WJ, Lin LF. Regional, age and respiratory-secretion-specific prevalence of respiratory viruses associated with asthma exacerbation: a literature review. Arch Virol. 2018 Apr;163(4):845-53.

46 Van Bever HP, Chng SY, Goh DY. Childhood severe acute respiratory syndrome, coronavirus infections and asthma. Pediatr Allergy Immunol. 2004 Jun;15(3):206-9.

47 Tokuhira N, Shime N, Inoue M, Kawasaki T, Sakurai Y, Kurosaka N, et al.; Writing Committee of AH1N1 Investigators; Japanese Society of Intensive Care Medicine Pediatric Intensive Care Unit Network. Mechanically ventilated children with 2009 pandemic influenza A/H1N1: results from the National Pediatric Intensive Care Registry in Japan. Pediatr Crit Care Med. 2012 Sep;13(5):e294-8.

48 Ludvigsson JF. Systematic review of COVID-19 in children shows milder cases and a better prognosis than adults. Acta Paediatr. 2020 Jun;109(6):1088-95.

49 Woodruff PG, Modrek B, Choy DF, Jia G, Abbas AR, Ellwanger A, et al. T-helper type 2-driven inflammation defines major subphenotypes of asthma. Am J Respir Crit Care Med. 2009 Sep;180(5):388-95.

50 Zhu J, Ji P, Pang J, Zhong Z, Li H, He C, et al. Clinical characteristics of 3,062 COVID-19 patients: a meta-analysis. J Med Virol. 2020. doi: $10.1002 / j m v .2588$

51 Morais-Almeida M, Aguiar R, Martin B, Ansotegui IJ, Ebisawa M, Arruda LK, et al. COVID-19, asthma, and biologic therapies: what we need to know. World Allergy Organ J. 2020 May;100126:100126.

52 Sajuthi SP, DeFord P, Jackson ND, et al. Type 2 and interferon inflammation strongly regulate SARS- CoV-2 related gene expression in the airway epithelium. bioRxiv. 2020. doi: https://doi.org/10.1101/2020.04. 09.034454 .

53 Jackson DJ, Busse WW, Bacharier LB, Kattan M, O'Connor GT, Wood RA, et al. Association of respiratory allergy, asthma, and expression of the SARS-CoV-2 receptor ACE2. J Allergy Clin Immunol. 2020. doi: 10.1016/j. jaci.2020.04.009

54 Peters MC, Sajuthi S, Deford P, Christenson S, Rios CL, Montgomery MT, et al.; National Heart, Lung, and Blood Institute Severe Asthma Research Program-3 Investigators. COVID-19 related genes in sputum cells in asthma: relationship to demographic features and corticosteroids. Am J Respir Crit Care Med. 2020. doi: 10.1164/rccm.2020030821OC.

55 Yamaya M, Nishimura H, Deng X, Sugawara $\mathrm{M}$, Watanabe $\mathrm{O}$, Nomura $\mathrm{K}$, et al. Inhibitory effects of glycopyrronium, formoterol, and budesonide on coronavirus HCoV-229E replication and cytokine production by primary cultures of human nasal and tracheal epithelial cells. Respir Investig. 2020 May;58(3): $155-68$. 
56 Matsuyama S, Kawase M, Nao N, et al. The inhaled corticosteroid ciclesonide blocks coronavirus RNA replication by targeting viral NSP15. bioRxiv. 2020. doi: https://doi. org/10.1101/2020.03.11.987016.

57 Jeon S, Ko M, Lee J, et al. Identification of antiviral drug candidates against SARSCoV-2 from FDA-approved drugs. bioRxiv. 2020. doi: https://doi.org/10.1101/2020.03. 20.999730.

58 Dong X, Cao YY, Lu XX, Zhang JJ, Du H, Yan $\mathrm{YQ}$, et al. Eleven faces of coronavirus disease 2019. Allergy. 2020. doi: 10.1111/all.14289.

59 Global Initiative for Asthma. 2020 GINA report: global strategy for asthma management and prevention. 2020 [cited 2020 Apr 28]. Available from: www.ginasthma.org.

60 Halpin DM, Singh D, Hadfield RM. Inhaled corticosteroids and COVID-19: a systematic review and clinical perspective. Eur Respir J. 2020 May;55(5):2001009.
61 Klimek L, Jutel M, Akdis C, Bousquet J, Akdis $\mathrm{M}$, Bachert C, et al.; ARIA-MASK study group. Handling of allergen immunotherapy in the COVID-19 pandemic: an ARIA-EAACI statement. Allergy. 2020. doi: 10.1111/ all.14336.

62 Bousquet J, Akdis C, Jutel M, Bachert C, Klimek L, Agache I, et al.; ARIA-MASK study group. Intranasal corticosteroids in allergic rhinitis in COVID-19 infected patients: an ARIA-EAACI statement. Allergy. 2020. doi: 10.1111/all.14302.

63 Lee N, Allen Chan KC, Hui DS, Ng EK, Wu A, Chiu RW, et al. Effects of early corticosteroid treatment on plasma SARS-associated Coronavirus RNA concentrations in adult patients. J Clin Virol. 2004 Dec;31(4):304-9.
64 Arabi YM, Mandourah Y, Al-Hameed F, Sindi AA, Almekhlafi GA, Hussein MA, et al.; Saudi Critical Care Trial Group. Corticosteroid therapy for critically ill patients with Middle East Respiratory Syndrome. Am J Respir Crit Care Med. 2018 Mar;197(6):75767.

65 Levin M, Morais-Almeida M, Ansotegui IJ Bernstein J, Chang YS, Chikhladze M, et al. Acute asthma management during SARSCoV2-pandemic 2020. World Allergy Organ J. 2020 May;100125(5):100125.

66 Kaye L, Theye B, Smeenk I, Gondalia R, Barrett MA, Stempel DA. Changes in medication adherence among patients with asthma and COPD during the COVID-19 pandemic. J Alllergy Clin Immunol Practice. 2020. Available from: https://doi.org/10.1016/j.jaip.2020. 04.053.https://doi.org/https://doi.org/ 10.1016/j.jaip.2020.04.053. 